\title{
História vivida, história pensada
}

\author{
History lived, thought-out history
}

FALCON, Francisco José Calazans. Estudos de teoria da história e historiografia. Volume I: teoria da história. São Paulo: Hucitec, 2011, 206 p.

\section{Marcia Mansor D'Alessio}

mardalessio@uol.com.br

Professora livre-docente

Universidade Federal de São Paulo

Av. Higienópolis, 794/122

01238-000 - São Paulo - SP

Brasil

Palavras-chave

Conhecimento histórico; Historiador; Historiografia.

Keywords

Historic knowledge; Historian; Historiography. 
O professor Francisco José Calazans Falcon, referência do pensamento historiográfico e mestre de muitas gerações, apresenta uma coletânea de textos de sua autoria que, certamente, fará parte da história da historiografia brasileira, uma vez que, nela, mostra o desenrolar de seu pensamento sobre alguns dos vários temas por ele pesquisados e refletidos em sua prática no ofício de historiador.

Resulta difícil sintetizar os inúmeros temas trabalhados no espaço de uma resenha, dada a sua variedade. Nesse sentido, a opção foi destacar questões que sintetizam alguns dos problemas do conhecimento histórico que são, ao mesmo tempo, algumas das inquietações do autor. Trata-se de problemáticas que permeiam todos os textos, dando interessante organicidade ao trabalho como um todo. São elas: 1) o duplo significado da palavra "história"; 2) a crise da história; 3) o realismo histórico; 4) a pós- modernidade/totalidade-fragmentação; 5) a identidade da disciplina e de seu artífice na contemporaneidade.

Anunciada no primeiro texto exposto, esta é uma das assertivas estruturantes das reflexões: a aceleração do tempo, evidência assinalada pelos historiadores contemporâneos, complexifica a reflexão histórica e a construção do discurso historiográfico. Um saber que se dedica a observar o que já aconteceu defronta-se com a rapidez do acontecido, que dá a sensação de um presente eterno e torna fugidio tanto o próprio presente, quanto o pretendido passado. Daí a inquietação: qual o (tempo?) "regime de historicidade" do historiador contemporâneo? A esse impasse, acrescentar-se-á a ambiguidade, na expressão do autor, da palavra "história":

Entre a História concebida como processo ou acontecer real, espécie de devir geral das sociedades, ou seja, realidade imanente, ou transcendente, e a História entendida como um processo de conhecimento, ao mesmo tempo atividade cognoscitiva e produto dessa mesma atividade que se materializa geralmente em "textos" [...] (FALCON 2011, p. 15).

Essa preocupação, que é compartilhada por Falcon com Pierre Vilar, bastante citado nos textos, aparece em, praticamente, todas as reflexões do autor nesta coletânea. O reconhecimento dos dois significados da palavra "história" ganha ênfase com a introdução da noção de "representação" no vocabulário historiográfico. Essa introdução levanta uma indagação a respeito do lugar do "real" no conhecimento histórico, uma vez que o uso indiscriminado da noção de representação pode obscurecer o estatuto ontológico do passado. O recurso a essa ameaça está na busca da concretude dos acontecimentos, ou seja, na busca da realidade extradiscursiva.

O ponto de partida da análise da mencionada crise é a expressão "vazio de ideias", trazida pelo intelectual português Eduardo Prado Coelho para explicar a situação da cultura atual. A fórmula incita a polêmica em torno da objetividade/verdade no conhecimento histórico, já que alude a uma indefinição dos fundamentos que referenciam verdades, o que compromete o conhecimento histórico, ameaçando sua utilidade.

A ideia de "fim da história" é mais uma das manifestações do que seria a crise do saber histórico. Citando de maneira recorrente essa polêmica, Falcon 
sugere sua posição por meio de uma instigante pergunta, formulada nestas bases: quando se fala em crise da história, de que história está se falando, da história-matéria ou da História-disciplina? A partir daí, o autor nega o fim da história, atribuindo essa sensação aos impasses encontrados pelo historiador atual a respeito da construção de seu próprio conhecimento em função da passagem de um tempo de certezas para um tempo de indefinições:

[...] como bem sentimos e sabemos, a História não chegou ao fim, se é que ela o possui. A História continua, pois os homens e suas sociedades continuam a existir. Não devemos misturar as coisas; não atribuamos à História problemas e perplexidades, insuficiências, sobretudo, que são exclusivamente nossos [...] Em termos mais claros: os obstáculos que enfrentamos em relação à História derivam quase que exclusivamente dos problemas e indefinições ora existentes dentro da Oficina do Historiador (FALCON 2011, p. 28).

Há movimentos na história produtores de fenômenos que marcam épocas, delimitam espaços, nominam situações vividas. Às profundas transformações dos séculos XVIII e XIX, situadas em uma região que abrigou países econômica e politicamente dominantes, os pensadores chamaram "modernidade", denominação emprestada de uma época anterior, classificada pela historiografia como Idade Moderna.

As práticas ou experiências históricas reconheceram o conceito e aceitaram o significado. Algumas pessoas enxergaram, por exemplo, a industrialização como um fenômeno produtor de situações "modernas". Assim, justifica-se o uso dessa datação - modernidade - pelo autor para discutir o que considera como contexto gerador de, pelo menos, duas possibilidades de abordagem disponíveis ao historiador: a analítico-explicativa e a hermenêutico-compreensiva.

A primeira constrói uma narrativa que obedece à lógica da temporalidade cronológica, ao investigar os componentes da modernidade a partir de seus "começos ou [...] origens na época que imediatamente a precede historicamente" (FALCON 2011, p. 40). A segunda "inverte a posição da primeira", o que é explicado como sendo metodologicamente a busca, pelo historiador, do reconhecimento, identificação e vivência da modernidade "pelos próprios atores históricos (indivíduos ou grupos sociais) nela e por ela envolvidos" (FALCON 2011, p. 40). E Falcon infere que: "Neste caso, torna-se fundamental investigar a semântica histórica, a produção literária e artística, o discurso político e o discurso historiográfico propriamente dito" (FALCON 2011, p. 40). Isso explica a fórmula por ele aplicada da abordagem "hermenêutico-compreensiva", o que abre a possibilidade de pensar a hermenêutica como um dos fatores responsáveis pela introdução da subjetividade e da sensibilidade no discurso historiográfico, uma das conquistas metodológicas do saber histórico do fim do século XX. Pode-se dizer, ainda, que é a perspectiva hermenêutica a que possibilita a historicização do fenômeno "modernidade", porque ela privilegia a existência e a consciência dos agentes históricos do fenômeno, os quais percebem a diferença e/ou a especificidade do momento histórico vivido. Ao estudar a modernidade, o autor estuda as metamorfoses na vivência da temporalidade, na relação dos agentes 
históricos com o tempo ("regime de historicidade") e no conceito de tempo no período situado no fim do século XVIII e no começo do século XIX.

Pode-se dizer que o "realismo histórico" é uma das grandes preocupações manifestadas, de uma forma ou de outra, nos textos aqui apresentados. Essa fórmula pode ser compreendida como uma aceitação, se não uma defesa, do estatuto ontológico da história-vivida (ou história-objeto, na expressão de Pierre Vilar). Está contemplada nessa discussão a questão da "verdade" (que já foi tratada, como visto, em outros momentos do texto) nos estudos históricos, negada por algumas tendências historiográficas sob o argumento da impossibilidade de atingi-la em função do objeto analisado não existir mais, porém seguidamente reafirmada pela maioria que a defende:

A escrita da história, produto de fatores múltiplos e complexos, como bem o sublinhou M. de Certeau, ao analisar a "operação historiográfica", não renunciou, até agora, à antiga intenção de ser um conhecimento verdadeiro, de "dizer a verdade sobre aquilo que foi", ou seja, ainda que se lhe possa questionar o caráter "científico", a história (disciplina) não parece disposta a renunciar à sua diferença em face do discurso ficcional (FALCON 2011, p. 167).

Isso não implica a crença de uma verdade absoluta e/ou a-histórica; pelo contrário, o conceito de verdade, como todo fato cultural, foi sendo historicizado pelas reflexões epistemológicas.

Uma vez aceita a premissa de que o historiador busca a verdade da história, ficou cada vez mais estabelecido pela historiografia que o instrumento para atingi-la são as fontes documentais. Falcon historiciza a relação do historiador com as fontes e seu uso nos diferentes procedimentos metodológicos adotados, situando, inclusive, o realismo histórico na tendência historiográfica que ele chama de "modernista".

Se a "historiografia moderna", para usar a noção do autor, acreditou na correspondência entre discurso e elementos extradiscursivos, ou seja, na relação entre história-pensada e história-vivida, a visão pós-moderna trabalha em sentido contrário. Para os pós-modernos, a representação historiográfica não pode referenciar-se em algo fora dela, porque o passado é sempre imaginado, uma existência ausente, ele próprio uma representação. Poder-se-ia dizer que, nesse sentido, portanto, o discurso historiográfico é uma metarrepresentação. Assim, deixa de ter sentido a inquietação em torno do binômio real/representação, dada a impossibilidade de acesso ao que seria o real, o que leva à renúncia da busca da verdade histórica por ser considerada desnecessária e inútil.

A linguística vem sendo apontada como um dos principais fatores dessas metamorfoses na epistemologia da história. A expressão "giro linguístico" é indicativa do surgimento de um verdadeiro campo de reflexão, dada a importância das questões colocadas pela surpreendente relação da história com a linguística.

Não é mera coincidência a simultaneidade entre o surgimento de posturas pós-modernas e a fragmentação do discurso historiográfico. Pelo contrário, este conjunto de transformações ontológicas e epistemológicas que se entende como pós-modernidade incide sobre a escrita da história. 
Duas questões chamam a atenção, dentre os muitos fatores analisados por Falcon para explicar a fragmentação da historiografia: a rejeição da ideia de totalidade, fechando, neste aspecto, a era do iluminismo e o retorno do sujeito, agora observado cuidadosamente na realidade e descrito detalhadamente no discurso. Ainda há, segundo o autor, nessa volta do sujeito como agente histórico, a revalorização do papel do historiador na composição de seu discurso, o que reforça a mencionada fragmentação:

A hipertrofia do sujeito-historiador torna-o a única instância de decisão a respeito da validade de um tema de pesquisa e do tipo de discurso mais adequado: problemas, métodos e resultados são sempre da exclusiva alçada do historiador: logo a fragmentação é inevitável (FALCON 2011, p. 177).

Francisco Falcon considera que não foi a diversidade de objetos investigados o que comprometeu a identidade do saber histórico, mas a grande especialização dos campos construídos para investigação. O resultado foi que cada temática busca sua própria legitimação no universo da pesquisa. Poder-se-ia acrescentar que essa busca se faz, dentre outras formas, pelas diferentes parcerias da história com outros saberes, o que resulta na multiplicação de procedimentos metodológicos. Essas múltiplas articulações provocam tensões e disputas, trazendo uma dupla hesitação: em relação ao fazer histórico e em relação à identidade do historiador:

Em face de tantas variações sobre o mesmo tema - a História - os conflitos são de certa maneira inevitáveis uma vez que cada tendência constitui um microcosmo cuja visão do ofício do historiador raramente se ajusta às demais. Logo, é a própria identidade do historiador que se fragmentou (FALCON 2011, p. 68).

Pelos limites de uma resenha, este levantamento de questões visou apenas a apresentar algumas das reflexões de um autor cuja obra sempre revela o "estado da arte" nos estudos históricos e que, há muito, orienta os caminhos da historiografia brasileira. A importância das questões analisadas e a plenitude das reflexões sobre elas são um convite à leitura deste livro, que aparece para enriquecer o estudo da escrita da história. 